\title{
Therapeutic opportunities for cancers presented by natural and synthetic compounds targeting the Hippo signaling pathway
}

\author{
Thanapon Charoenwongpaiboon $^{\mathrm{a}}$, Chuti Laowtammathron ${ }^{\mathrm{b}}$, Chanchao Lorthongpanich ${ }^{\mathrm{b}, *}$ \\ a Department of Chemistry, Faculty of Science, Silpakorn University, Nakhon Pathom 73000 Thailand \\ b Siriraj Center of Excellence for Stem Cell Research, Department of Medicine, Faculty of Medicine Siriraj \\ Hospital, Mahidol University, Bangkok 10700 Thailand
}

*Corresponding author, e-mail: chanchao.lor@mahidol.ac.th

Received 30 Sep 2021

Accepted 7 Oct 2021

\begin{abstract}
A new trend in anti-cancer treatments through the disruption of the YAP-TEAD protein-protein interaction complex is recognized. YAP has been tipped as a key modulator of the Hippo signaling pathway. Binding of YAP to its transcription factor TEAD can lead to disease progression as it drives cell-proliferation and triggers anti-apoptosis signaling. Recent studies have uncovered promising activities of various small molecules for regulating components of the Hippo signaling pathway. By using a structural elucidation and computational approach, some small molecules are able to bind on the YAP-TEAD interaction interface and inhibit the Hippo pathway. This review highlights our current understanding of how natural and synthetic molecules regulate Hippo signaling activity and suggests how phytochemical compounds available today can target the YAP-TEAD protein interaction complex to eradicate cancer cells.
\end{abstract}

KEYWORDS: YAP-TAED proteins, Hippo signaling pathway, cancer therapy, apoptosis, phytochemicals

\section{INTRODUCTION}

Phytochemicals are compounds produced by plants, vegetables, grains, beans, and fruits. These compounds are regarded as important medicinal products that provide health benefits in humans. Generally, phytochemicals are classified into two groups: primary compounds (i.e., chlorophyll, proteins, and sugars) and secondary compounds (i.e., terpenoids, alkaloids, flavonoids, and phenolic) [1]. Some of these phytochemicals, especially secondary compounds, display a cytoprotection effect and safeguard the cells against cancer-causing damages [1-3]. However, insight into the mechanism affected by phytochemicals such as cell protection and anti-cancer properties is not well understood.

Synthetic small molecules have been synthesized to target cancer cells. Many of these molecules are used as therapeutic drugs to treat cancer. For example, tamoxifen is used to treat breast cancer [4] and cytarabine to cure acute myeloid leukemia [5]. However, several small molecules are still being examined for anti-cancer activity as researchers attempt to identify the molecular mechanism underlying their mode of action. In fact, small molecules can act differently in the oncogenic gene/proteins depending on their chemical properties and structures. However, small molecules that can disrupt the protein-protein interaction complex are ideal as they can potentially inhibit binding of oncogenic proteins to their transcription factor(s) and hence make them inactive.

The Hippo (hpo) gene plays a crucial role in regulating Drosophila cell proliferation and apoptosis and was first identified in 1995 [6, 7]. Later, proteins involved in regulating the expression and function of the hpo gene were identified (i.e., Wart, Scallop, Yokie). These proteins work together to orchestrate functions of the cells, particularly cell proliferation and apoptosis, through a cell-contact inhibition mechanism later described as the Hippo signaling pathway. After the Hippo signaling pathway in Drosophila was identified, more studies were carried out in other animal species, including humans. The result revealed the evolutionary conservation of Hippo signaling among Drosophila, human, and other mammals such as mice, pig, and companion animals such as felines and canines [8]. Not only was the signaling cascade highly conserved in species, the functional redundancy of the Hippo's 
component proteins was also demonstrated, such as the ability of the human LATS1/2 to rescue the mouse Lat $1 / 2$ deficient phenotype [9]. Although Hippo components and functions may have deep evolutionary roots, several comparative analyses have recently traced hippo components in an ancestor species and revealed its role in regulating the growth of cnidarians, bilaterians, non-metazoan and unicellular organisms. Despite having only one or two Hippo pathway components, their functions in unicellular organisms are conserved compared to those corresponded in humans [10].

As the Hippo pathway can regulate several biological processes, including cellular and immune homeostasis, regeneration and repair, and cancer development, it has become a central focus point in both basic and translational research. The dysregulation of the Hippo component proteins leads to a variety of misregulations in transcription mechanism, unlimited cell proliferation, and tumorigenesis. Multiple efforts to target key regulators of the Hippo pathway for cancer treatment have been reported. These are associated with the targeting of key effector proteins, including YAP/TAZ and TEAD interactions [11].

In this review, we highlight the latest research on natural products, with a focus on phytochemical compounds that target Hippo component proteins in various types of cancers. In addition, binding of a compound to a pocket of YAP-TEAD protein complex was demonstrated. We believe this review can help researchers design new drugs targeting the Hippo signaling pathway using natural compounds as therapeutic agents for cancer therapy.

\section{HIPPO SIGNALING CASCADE}

In mammalian systems, the hippo pathway contains four core components that regulate through phosphorylation, namely mammalian STE20-like kinase (MST), large tumor suppressor kinase (LATS), scaffold protein Salvador homolog 1 (SAV1), and MOB kinase activator 1 (MOB1) (Fig. 1). When the Hippo pathway is on, MST1/2 kinase is automatically activated by auto-phosphorylation and forms a complex with SAV1. The activated MST1/2 subsequently phosphorylates and activates LATS1/2 and MOB1. In turn, the activated LATS1/2 phosphorylates the yes-associated protein (YAP) and WW domain-containing transcription regulator protein 1 (TAZ). Phosphorylation of YAP and TAZ inhibits their nuclear translocation via 14-3-3 binding and promotes proteasome-dependent degradation. On

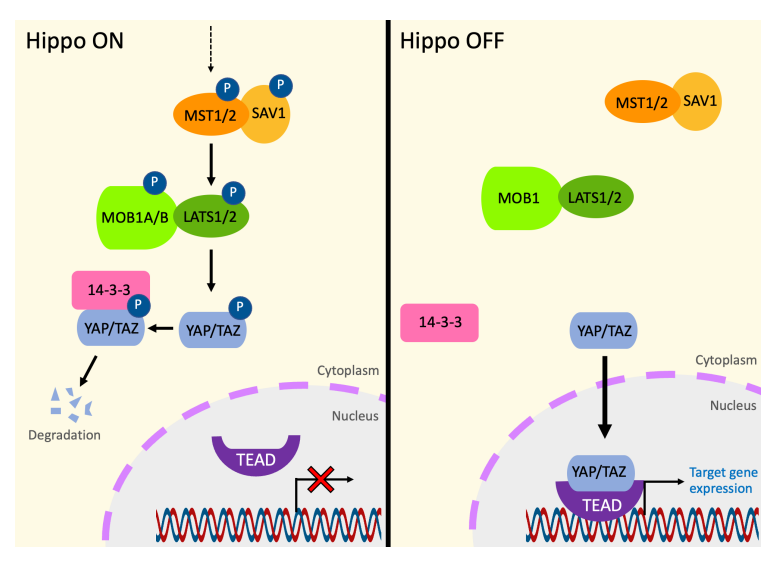

Fig. 1 Overview of the Hippo signaling pathway in mammals.

the contrary, un-phosphorylated YAP localizes in the nucleus and binds with TEAD1-4 transcription factors, initiating the transcription of genes required in cell proliferation and survival.

\section{DYSREGULATION OF HIPPO SIGNALING CASCADE RESULTS IN CANCERS}

The Hippo signaling pathway is emerging as a tumor suppressing method in which dysregulation enhances the activation of various target oncogenes, leading to hyperproliferation, migration, anti-apoptosis, and chemotherapeutic resistance to various cancer cells such as lung cancer [12-14]], ovarian cancer [15], breast cancer [16,17] and colorectal cancer [18]. Up-regulation of YAP and/or TAZ is often identified in solid cancers, so YAP and TAZ are regarded as potent oncogenes in several types of cancers. However, their role in hematologic malignancies is controversial. While loss of upstream Hippo component core kinases and upregulation of YAP has been noted in leukemia and lymphomas $[19,20]$, the expression of YAP induces apoptosis in multiple myeloma through the induction of the Abl1-dependent DNA damage mechanism [21], which works against the oncogenic role of YAP and TAZ in some hematological malignancies.

\section{NATURAL COMPOUNDS TARGETING THE HIPPO SIGNALING PATHWAY}

There is evidence that many natural compounds derived from plants, such as flavonoids, stilbenoids, and alkaloids, can modulate the expression at both the mRNA and protein levels and the phosphorylation of some Hippo signaling components such as MST1/2, LAST1/2, YAP, and TAZ (Table 1). 
Table 1 Natural compounds that target the Hippo signaling pathway.

\begin{tabular}{|c|c|c|c|}
\hline Compound & Structure & Cell line/Mechanism & Ref. \\
\hline Fisetin & & $\begin{array}{l}\text { In human osteosarcoma cells } \\
\text { - Increase phosphorylation of MST1/2, LATS2, and YAP via ZAK } \alpha \text { activation } \\
\text { In human MSC and SaOs-2 cells } \\
\text { - Decrease expression of YAP at the protein level } \\
\text { - Inhibit proliferation, migration, and osteogenic differentiation }\end{array}$ & $\begin{array}{l}{[38]} \\
{[28]}\end{array}$ \\
\hline Quercetin & & $\begin{array}{l}\text { In mouse glomerular mesangial cells } \\
\text { - Inhibit high glucose-induced MC proliferation } \\
\text { - Increase the phosphorylation level of MST1 and LATS1 } \\
\text { - Reduce the expression of nuclear YAP and YAP-TEAD complex induced by high } \\
\text { glucose levels }\end{array}$ & [39] \\
\hline Liquiritigenin & & $\begin{array}{l}\text { In human HSC cells } \\
\text { - Increase phosphorylation of LATS1 and YAP } \\
\text { - Prevent translocation of YAP to the nucleus } \\
\text { - Suppress the expression of TGF- } \beta 1 / \text { Smad }\end{array}$ & {$[40]$} \\
\hline Luteolin & & $\begin{array}{l}\text { In human and mouse TNBC cells } \\
\text { - Induce phosphorylation and degradation of YAP/TAZ } \\
\text { - Reduce transcriptional activity and nuclear translocation of YAP/TAZ } \\
\text { - Suppress the migration of TNBC cells }\end{array}$ & {$[41]$} \\
\hline $\begin{array}{l}\text { Epigallocatechin- } \\
\text { 3-gallate }\end{array}$ & & $\begin{array}{l}\text { In mouse myoblast cells } \\
\text { - Increase myogenic differentiation } \\
\text { - Reduce phosphorylation of TAZ and LATS1, not MST1/2 } \\
\text { - Increase translocation of TAZ to nucleus } \\
\text { In Tongue squamous cell carcinoma } \\
\text { - Decrease LATS1 and MOB1 protein levels } \\
\text { - Reduce the total level of TAZ and phosphorylated TAZ }\end{array}$ & [29] \\
\hline Naringin & & $\begin{array}{l}\text { In human endothelial cells } \\
\text { - Restore ox-LDL-induced YAP down-regulation and apoptosis }\end{array}$ & [43] \\
\hline Resveratrol & & $\begin{array}{l}\text { In human pancreatic cancer cells } \\
\text { - Suppress cell proliferation and induce apoptosis } \\
\text { - Decrease expression of YAP at the mRNA and protein levels } \\
\text { - Increase phosphorylation level of YAP } \\
\text { - Decrease translocation of YAP to the nucleus } \\
\text { In human breast cancer cells } \\
\text { - Decrease the expression of YAP target genes, including AREG, CTGF and CYR61 } \\
\text { - Inactivate RhoA, leading to activation of LATS1 and induction of YAP phosphoryla- } \\
\text { tion } \\
\text { In human thyroid FTC238 cells } \\
\text { - Increase expression of phosphorylated MST1/2, LATS1, and YAP } \\
\text { - Decrease nuclear YAP and TAZ expression }\end{array}$ & [44] \\
\hline Emodin & & $\begin{array}{l}\text { In human HepG2 cells } \\
\text { - Induce the phosphorylation of LATS1 and YAP } \\
\text { - Increase expression of YAP, LATS1, and MOB1B at the mRNA level }\end{array}$ & {$[31]$} \\
\hline Decursin & & $\begin{array}{l}\text { In human HepG2 cells } \\
\text { - Decrease total protein level of YAP, but not its mRNA } \\
\text { - Increase phosphorylation level of YAP and LATS1, which inhibits nuclear transloca- } \\
\text { tion of YAP } \\
\text { - Suppress the growth and arrest the cell cycle but promote cell apoptosis }\end{array}$ & {$[32]$} \\
\hline Matrine & & $\begin{array}{l}\text { Human SW480 colorectal cancer cells } \\
\text { - Increase expression of LATS2 at the protein level } \\
\text { - Inhibit cell viability }\end{array}$ & [35] \\
\hline Sophoridine & & $\begin{array}{l}\text { In human lung cancer cells } \\
\text { - Suppress proliferation, colony formation, and migration of lung cancer cells } \\
\text { - Increase expression of LATS1/2, MST1/2, and phosphorylated YAP } \\
\text { - Downregulate the expression of some Hippo pathway target genes such as CYR61, } \\
C D X 2, \text { FOXM1, c-MYC, and VEGF at the mRNA level }\end{array}$ & [36] \\
\hline Tetrandrine & & $\begin{array}{l}\text { In human neuroblastoma cells } \\
\text { - Inhibit proliferation and induce apoptosis } \\
\text { - Increase phosphorylation level of LATS1/2 and YAP } \\
\text { - Decrease translocation of YAP to nucleus } \\
\text { - Decrease expression of YAP at the protein level }\end{array}$ & {$[37]$} \\
\hline
\end{tabular}


Flavonoids and stilbenoids are plant polyphenols that play an essential role in plants' defensive response $[2,3]$. They possess antioxidants, antibacterial, antiviral, anti-allergic, and anti-inflammatory properties [22-24] and are known as anticancer agents that modulate a variety of signal transduction pathways in cancer cells [25-27]. Various researchers have demonstrated that flavonoids (i.e., fisetin, quercetin, liquiritigenin, luteolin, naringin) and stilbenoids (i.e., resveratrol) can inhibit the proliferation, migration, and differentiation of cancer cells and induce cell apoptosis. In the case of the Hippo signaling pathway, flavonoids and stilbenoids increase the phosphorylated form of upstream components of YAP, such as MST1/2 and LATS1. This consequently decreases the phosphorylation and nuclear translocation of YAP and TAZ. In addition, a recent study demonstrated that flavonoids might play a role as YAP-TEAD complex disruptors that bind to the YAP-TEAD interaction interface [28]. Nevertheless, epigallocatechin-3-gallate, the main flavonoid in green tea, has the reverse effect in mouse myoblasts. This compound significantly reduces phosphorylation levels of LATS1 and TAZ (not MST1/2) and increases the nuclear translocation of TAZ and myogenic differentiation [29].

Emodin, a natural anthraquinone found in several Chinese herbs, has a broad spectrum of biological functions such as antiviral, antibacterial, anti-allergic, anti-osteoporotic, anti-diabetic, and anti-inflammatory activities [30]. A recent study showed that emodin can attenuate oxidative damage in the hepatocyte cell line and in mice via the activation of the AMPK and Hippo signaling pathways. This compound increases phosphorylation of LATS1 and YAP, and induces mRNA expression of several genes targeting signaling of the AMPK and Hippo pathways such as Prkaa1 (AMP-activated protein kinase catalytic subunit $\alpha-1$ ), YAP, LATS1, and MOB1B [31]. Likewise, decursin, a compound isolated from the root of the Korean Dang Gui, can also induce phosphorylation of LATS1 and YAP, and decrease expression of YAP at the protein level (but not mRNA) [32]. This inhibits the growth of HepG2 liver cancer cells by suppressing cell proliferation, arresting the cell cycle, and promoting apoptosis.

Alkaloids are another class of natural compounds that have shown promising anticancer activity and been developed into anticancer drugs $[33,34]$. The mechanisms responsible for the anticancer effects of some alkaloids have been proposed, including the Hippo signaling pathway. Alkaloids play an important role in the expression and phosphorylation of some Hippo signaling proteins. For example, matrine induces protein expression of LATS2 [35]; sophoridine induces protein expression of both LATS1/2, MST1/2, and phosphorylated YAP [36]; tetrandrine suppresses expression of YAP, induces the phosphorylation of LATS1/2 and YAP, and decreases nuclear translocation of YAP [37]. Taken together, various natural compounds can inhibit oncogenic transcriptional programs.

\section{DISRUPTION OF YAP-TEAD COMPLEX BY SMALL MOLECULES}

The TEAD family of transcription factors are known as the transcriptional output of the Hippo signaling pathway. They consist of four isoforms (TEAD1-4 in humans) that share similar domain architecture $[47,48]$. TEADs must pair with YAP/TAZ to regulate transcription. Disruption of YAP-TEAD association can suppress oncogenesis and the expression of downstream genes involved in cell proliferation and cell death. A number of studies show that some small molecules can specifically bind to the YAPTEAD interaction interface and reduce their affinity, resulting in reduction of YAP activity. Verteporfin is a well-known example of YAP-TEAD interaction disruptors [49-51]. Structural determination of the YAP-TEAD complex provides clear and detailed insight into the interaction [52-55]. The N-terminal of YAP interacts with TEAD and forms three interaction interfaces (Fig. 2).

Interface 1 is mediated by intermolecular hydrogen bonds between the backbones of YAP $\beta 1$ and TEAD $\beta 7$. In comparison to the other two interfaces, this type has poor binding affinity [53]. Interface 2 is formed when $\alpha$-helix of YAP positions into the helix-turn-helix pocket of TEAD. The hydrophobic leucine residues of YAP are key contact residues. Small molecules and peptides specifically bind to TEAD at this interaction interface (Fig. 2) [56, 57]. Interface 3 is the most significant in YAP-TEAD interaction and it alone is sufficient for complex formation [53]. At this interface, YAP forms a structure that resembles the Greek letter $\Omega$, and three hydrophobic residues (M86, L91, and F95 in human YAP) fit into the pocket on the TEAD interface. TEAD residues that form this interaction are highly conserved and therefore, it is challenging to design a peptide that selectively binds at this interface. Small molecules, such as flufenamic acid [58], triazole carbohydrazide derivative [59], and compound 3 and 3.1 [60], can inhibit Hippo activity by occupying the pocket 3 interface on TEAD (Fig. 2).

Besides the TEAD interface, TEAD also contains 


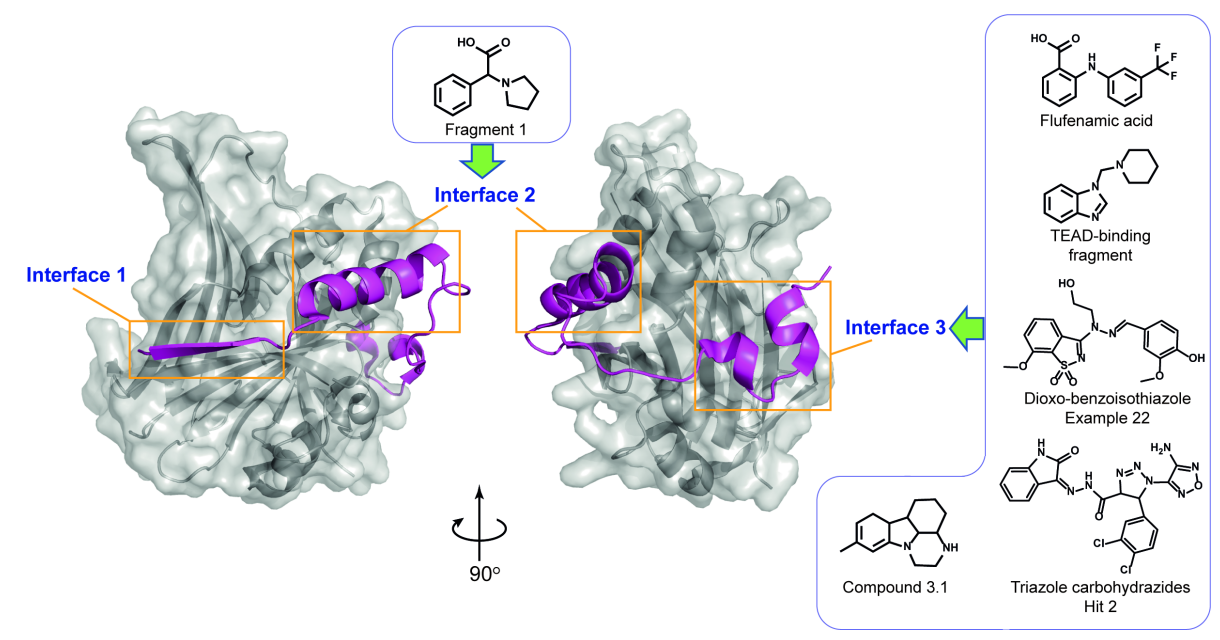

Fig. 2 Compounds that target the TEAD surface pocket at interface 2 and 3 (PDB ID: 3KYS).
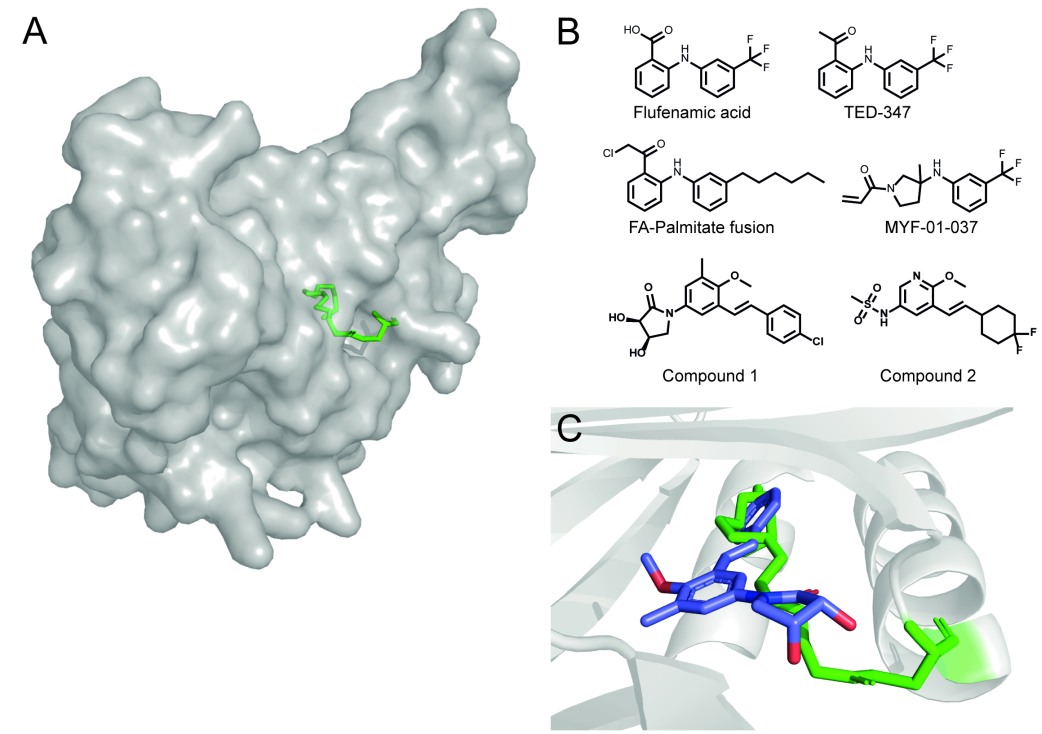

Fig. 3 (A) Surface structure of the palmitate-bound TEAD (PDB ID: 3KYS). Palmitate covalently bound on TEAD central pocket is shown in green. (B) Compounds that target the TEAD hydrophobic central pocket. (C) Overlay of Compound 1 and palmitate-bound TEAD.

a hydrophobic pocket that is possibly occupied by small molecules. One end of the pocket is solventexposed, while the other end extends into the interior and binds to palmitate (Fig. 3). Noland and colleagues reported that palmitoylation is required for proper TEAD folding and stability [61]. Some small molecules specifically bind to this pocket to inhibit palmitoylation and YAP-TEAD interaction $[58,62-65]$.

\section{CONCLUSION AND FUTURE PERSPECTIVES}

A number of pharmacological compounds such as synthetic small molecules, synthetic peptides, and food or plant-derived natural compounds are being studied for their therapeutic potential, especially for cancer treatment. Hippo signaling is now regarded as an oncogenic pathway and has become a promising target for the treatment of both solid and hematologic cancers.

Medicinal recipes using herbs and natural compounds for cancer prevention has been routine practice for those with health concerns. Given that targeting the Hippo signaling pathway is a prospective anti-cancer treatment, discovering natural compounds targeting YAP-TEAD activity is necessary for the development of natural compound-based cancer 
therapy.

It is important to note that YAP is a dual function protein. Contradicting findings that define YAP as an oncogene, some studies have shown the tumor suppressive function of YAP (i.e., expression of YAP induces apoptosis in multiple myeloma, loss of YAP protecting breast cancer cells from anoikis, and ability to induce cell death in head and neck cancer cells). Therefore, it is important to pay attention to the molecular mechanisms that dictate YAP/TAZ functions, either as an oncogene or a tumor suppressor in the particular cell type. This clarification is important for the selection of natural compounds for anti-cancer treatment when considering YAP/TAZtargeted therapies. Such understanding could also lead to the development of diet therapy programs for disease prevention in the future.

Acknowledgements: CLa and CLo were supported by a grant from the Faculty of Medicine Siriraj Hospital, Mahidol University and the National Research Council of Thailand (NRCT), grant no. NRCT5-RSA63015-13 for CLa and grant no. N41A640154 for CLo.

\section{REFERENCES}

1. Liu RH (2004) Potential synergy of phytochemicals in cancer prevention: mechanism of action. J Nutr 134, 3479S-3485S.

2. Panche AN, Diwan AD, Chandra SR (2016) Flavonoids: an overview. J Nutr Sci 5, e47.

3. Mathesius U (2018) Flavonoid functions in plants and their interactions with other organisms. Plants 7, ID 30.

4. Jordan VC (2006) Tamoxifen (ICI46,474) as a targeted therapy to treat and prevent breast cancer. $\mathrm{Br}$ J Pharmacol 147S1, S269-S276.

5. Reese ND, Schiller GJ (2013) High-dose cytarabine (HD araC) in the treatment of leukemias: a review. Curr Hematol Malig Rep 8, 141-148.

6. Justice RW, Zilian O, Woods DF, Noll M, Bryant PJ (1995) The Drosophila tumor suppressor gene warts encodes a homolog of human myotonic dystrophy kinase and is required for the control of cell shape and proliferation. Genes Dev 9, 534-546.

7. Xu T, Wang W, Zhang S, Stewart RA, Yu W (1995) Identifying tumor suppressors in genetic mosaics: the Drosophila lats gene encodes a putative protein kinase. Development 121, 1053-1063.

8. Budel SJ, Penning MM, Penning LC (2021) Hippo signaling pathway in companion animal diseases, an under investigated signaling cascade. Vet $Q \mathbf{4 1}$, 172-180.

9. Lorthongpanich C, Doris TP, Limviphuvadh V, Knowles BB, Solter D (2012) Developmental fate and lineage commitment of singled mouse blastomeres. Development 139, 3722-3731.

10. Chen Y, Han H, Seo G, Vargas RE, Yang B, Chuc K, Zhao H, Wang W (2020) Systematic analysis of the Hippo pathway organization and oncogenic alteration in evolution. Sci Rep 10, iD 3173.

11. Calses PC, Crawford JJ, Lill JR, Dey A (2019) Hippo pathway in cancer: aberrant regulation and therapeutic opportunities. Trends Cancer 5, 297-307.

12. Lee JE, Park HS, Lee D, Yoo G, Kim T, Jeon H, Yeo M-K, Lee C-S, et al (2016) Hippo pathway effector YAP inhibition restores the sensitivity of EGFR-TKI in lung adenocarcinoma having primary or acquired EGFR-TKI resistance. Biochem Biophys Res Commun 474, 154-160.

13. Hsu P-C, You B, Yang Y-L, Zhang W-Q, Wang Y-C, Xu Z, Dai Y, Liu S, et al (2016) YAP promotes erlotinib resistance in human non-small cell lung cancer cells. Oncotarget 7, 51922-51933.

14. McGowan M, Kleinberg L, Halvorsen AR, Helland $\AA$, Brustugun OT (2017) NSCLC depend upon YAP expression and nuclear localization after acquiring resistance to EGFR inhibitors. Genes Cancer 8, 497-504.

15. Huang JM, Nagatomo I, Suzuki E, Mizuno T, Kumagai T, Berezov A, Zhang H, Karlan B, et al (2013) YAP modifies cancer cell sensitivity to EGFR and survivin inhibitors and is negatively regulated by the nonreceptor type protein tyrosine phosphatase 14 . Oncogene 32, 2220-2229.

16. Lin C-H, Pelissier FA, Zhang H, Lakins J, Weaver VM, Park C, LaBarge MA (2015) Microenvironment rigidity modulates responses to the HER2 receptor tyrosine kinase inhibitor lapatinib via YAP and TAZ transcription factors. Mol Biol Cell 26, 3946-3953.

17. Li Z, Razavi P, Li Q, Toy W, Liu B, Ping C, Hsieh W, Sanchez-Vega F, et al (2018) Loss of the FAT1 tumor suppressor promotes resistance to CDK4/ 6 inhibitors via the Hippo pathway. Cancer Cell 34, 893-905.

18. Liu BS, Xia HW, Zhou S, Liu Q, Tang QL, Bi NX, Zhou JT, Gong QY, et al (2018) Inhibition of YAP reverses primary resistance to EGFR inhibitors in colorectal cancer cells. Oncol Rep 40, 2171-2182.

19. Kim TS, Lee DH, Kim SK, Shin SY, Seo EJ, Lim DS (2012) Mammalian sterile 20-like kinase 1 suppresses lymphoma development by promoting faithful chromosome segregation. Cancer Res 72, 5386-5395.

20. Hartmann EM, Campo E, Wright G, Lenz G, Salaverria I, Jares P, Xiao W, Braziel RM, et al (2010) Pathway discovery in mantle cell lymphoma by integrated analysis of high-resolution gene expression and copy number profiling. Blood 116, 953-961.

21. Cottini F, Hideshima T, Xu C, Sattler M, Dori M, Agnelli L, ten Hacken E, Bertilaccio MT, et al (2014) Rescue of Hippo coactivator YAP1 triggers DNA damageinduced apoptosis in hematological cancers. Nat Med 
20, 599-606.

22. Huang Q, Guo Y, Fu R, Peng T, Zhang Y, Chen F (2014) Antioxidant activity of flavonoids from leaves of Jatropha curcas. ScienceAsia 40, 193-197.

23. Sribuhoma T, Saraphona C, Decharchoocharta P, Boonyaratb C, Yenjai C (2016) Acetylcholinesterase inhibition and cytotoxicity of flavonoids and chalcones from Derris indica. ScienceAsia 42, 247-251.

24. Chena J, Wanga R, Lia Y, Lid C, Liud T, Xine Y, Lib Y, Zhanga D (2021) Ginkgolic acid inhibits proliferation and migration of human hepatocellular carcinoma cells by inducing G0/G1 cell cycle arrest. ScienceAsia 47, 11-18.

25. Kopustinskiene DM, Jakstas V, Savickas A, Bernatoniene J (2020) Flavonoids as anticancer agents. Nutrients 12, ID 457.

26. Widowatia W, Jasaputraa DK, Heriadyb Y, Fariedc A, Rizald R, Widodod WS, Wibowod SHB, Kusumad HSW, et al (2019) Dietary flavonoids against various breast cancer subtypes: a molecular docking study. ScienceAsia 45, 452-457.

27. Senawong T, Khaopha S, Misuna S, Komaikul J, Senawong G, Wongphakham P, Yunchalard S (2014) Phenolic acid composition and anticancer activity against human cancer cell lines of the commercially available fermentation products of Houttuynia cordata. ScienceAsia 40, 420-427.

28. Lorthongpanich C, Charoenwongpaiboon T, Supakun P, Klaewkla M, Kheolamai P, Issaragrisil S (2021) Fisetin inhibits osteogenic differentiation of mesenchymal stem cells via the inhibition of YAP. Antioxidants 10, ID 879.

29. Kim AR, Kim KM, Byun MR, Hwang J-H, Park JI, Oh HT, Jeong MG, Hwang ES, et al (2017) (-)Epigallocatechin-3-gallate stimulates myogenic differentiation through TAZ activation. Biochem Biophys Res Commun 486, 378-384.

30. Dong X, Fu J, Yin X, Cao S, Li X, Lin L, Huyiligeqi, Ni J (2016) Emodin: A Review of its pharmacology, toxicity and pharmacokinetics. Phytother Res $\mathbf{3 0}$ 1207-1218.

31. Lee EH, Baek SY, Park JY, Kim YW (2020) Emodin in rheum undulatum inhibits oxidative stress in the liver via AMPK with Hippo/Yap signaling pathway. Pharm Biol 58, 333-341.

32. Li J, Wang H, Wang L, Tan R, Zhu M, Zhong X, Zhang Y, Chen B, et al (2018) Decursin inhibits the growth of HepG2 hepatocellular carcinoma cells via Hippo/YAP signaling pathway. Phytother Res 32, 2456-2465.

33. Gupta AP, Pandotra P, Kushwaha M, Khan S, Sharma R, Gupta S (2015) Alkaloids: a source of anticancer agents from nature. In: Atta-ur R (ed) Studies in Natural Products Chemistry, Elsevier, Vol 46, pp 341-445.

34. Lu J-J, Bao J-L, Chen X-P, Huang M, Wang Y-T (2012) Alkaloids Isolated from natural herbs as the anti- cancer agents. Evid Based Complement Alternat Med 2012, ID 485042.

35. Zhang Y, Wang M, Xu X, Liu Y, Xiao C (2019) Matrine promotes apoptosis in SW480 colorectal cancer cells via elevating MIEF1-related mitochondrial division in a manner dependent on LATS2-Hippo pathway. $J$ Cell Physiol 234, 22731-22741.

36. Zhu L, Huang S, Li J, Chen J, Yao Y, Li L, Guo H, Xiang $\mathrm{X}$, et al (2020) Sophoridine inhibits lung cancer cell growth and enhances cisplatin sensitivity through activation of the p53 and Hippo signaling pathways. Gene 742, ID 144556.

37. Zhao Q, Jia X, Zhang Y, Dong Y, Lei $Y$, Tan X, Williamson RA, Wang A, et al (2019) Tetrandrine induces apoptosis in human neuroblastoma through regulating the Hippo/YAP signaling pathway. Biochem Biophys Res Commun 513, 846-851.

38. Fu C-Y, Chen M-C, Tseng Y-S, Chen M-C, Zhou Z, Yang J-J, Lin Y-M, Viswanadha VP, et al (2019) Fisetin activates Hippo pathway and JNK/ERK/AP-1 signaling to inhibit proliferation and induce apoptosis of human osteosarcoma cells via ZAK overexpression. Environ Toxicol 34, 902-911.

39. Lei D, Chengcheng L, Xuan Q, Yibing C, Lei W, Hao Y, Xizhi L, Yuan L, et al (2019) Quercetin inhibited mesangial cell proliferation of early diabetic nephropathy through the Hippo pathway. Pharmacol Res 146, ID 104320.

40. Lee EH, Park K-I, Kim K-Y, Lee J-H, Jang EJ, Ku SK, Kim SC, Suk HY, et al (2019) Liquiritigenin inhibits hepatic fibrogenesis and TGF- $\beta 1 /$ Smad with Hippo/YAP signal. Phytomedicine 62, ID 152780.

41. Cao D, Zhu G-Y, Lu Y, Yang A, Chen D, Huang H-J, Peng S-X, Chen L-W, et al (2020) Luteolin suppresses epithelial-mesenchymal transition and migration of triple-negative breast cancer cells by inhibiting YAP/TAZ activity. Biomed Pharmacother 129, ID 110462.

42. Li A, Gu K, Wang Q, Chen X, Fu X, Wang Y, Wen Y (2018) Epigallocatechin-3-gallate affects the proliferation, apoptosis, migration and invasion of tongue squamous cell carcinoma through the hippo-TAZ signaling pathway. Int J Mol Med 42, 2615-2627.

43. Zhao H, Liu M, Liu H, Suo R, Lu C (2020) Naringin protects endothelial cells from apoptosis and inflammation by regulating the Hippo-YAP Pathway. Biosci Rep 40, BSR20193431.

44. Jiang Z, Chen X, Chen K, Sun L, Gao L, Zhou C, Lei M, Duan W, et al (2016) YAP inhibition by resveratrol via activation of AMPK enhances the sensitivity of pancreatic cancer cells to gemcitabine. Nutrients $\mathbf{8}$, ID 546.

45. Kim YN, Choe SR, Cho KH, Cho DY, Kang J, Park CG, Lee HY (2017) Resveratrol suppresses breast cancer cell invasion by inactivating a RhoA/YAP signaling axis. Exp Mol Med 49, e296.

46. Xu G, Chen J, Wang G, Xiao J, Zhang N, Chen Y, Yu H, Wang G, et al (2020) Resveratrol inhibits 
the tumorigenesis of follicular thyroid cancer via ST6GAL2-regulated activation of the hippo signaling pathway. Mol Ther Oncolytics 16, 124-133.

47. Huh HD, Kim DH, Jeong H-S, Park HW (2019) Regulation of TEAD transcription factors in cancer biology. Cells 8, ID 600.

48. Zhou Y, Huang T, Zhang J, Wong CC, Zhang B, Dong Y, Wu F, Tong JHM, et al (2017) TEAD1/4 exerts oncogenic role and is negatively regulated by miR-4269 in gastric tumorigenesis. Oncogene 36, 6518-6530.

49. Wei C, Li X (2020) Verteporfin inhibits cell proliferation and induces apoptosis in different subtypes of breast cancer cell lines without light activation. BMC Cancer 20, ID 1042.

50. Liu-Chittenden Y, Huang B, Shim JS, Chen Q, Lee S-J, Anders RA, Liu JO, Pan D (2012) Genetic and pharmacological disruption of the TEAD-YAP complex suppresses the oncogenic activity of YAP. Genes Dev 26, 1300-1305.

51. Wei C Li X (2020) The Role of photoactivated and non-photoactivated verteporfin on tumor. Front Pharmacol 11, ID 1626.

52. Kaan HYK, Chan SW, Tan SKJ, Guo F, Lim CJ, Hong W, Song H (2017) Crystal structure of TAZ-TEAD complex reveals a distinct interaction mode from that of YAP-TEAD complex. Sci Rep 7, ID 2035.

53. Li Z, Zhao B, Wang P, Chen F, Dong Z, Yang H, Guan K-L, Xu Y (2010) Structural insights into the YAP and TEAD complex. Genes Dev 24, 235-240.

54. Tian W, Yu J, Tomchick DR, Pan D, Luo X (2010) Structural and functional analysis of the YAP-binding domain of human TEAD2. Proc Natl Acad Sci USA 107, 7293-7298.

55. Bokhovchuk F, Mesrouze Y, Izaac A, Meyerhofer M, Zimmermann C, Fontana P, Schmelzle T, Erdmann D, et al (2019) Molecular and structural characterization of a TEAD mutation at the origin of Sveinsson's chorioretinal atrophy. FEBS $J$ 286, 2381-2398.

56. Crook ZR, Sevilla GP, Friend D, Brusniak M-Y, Bandaranayake $\mathrm{AD}$, Clarke $\mathrm{M}$, Gewe $\mathrm{M}$, Mhyre $\mathrm{AJ}$, et al (2017) Mammalian display screening of diverse cystine-dense peptides for difficult to drug targets. Nat Commun 8, ID 2244.

57. Kaan HYK, Sim AYL, Tan SKJ, Verma C, Song H (2017) Targeting YAP/TAZ-TEAD protein-protein in- teractions using fragment-based and computational modeling approaches. PLoS One 12, e0178381.

58. Pobbati AV, Han X, Hung AW, Weiguang S, Huda N, Chen G-Y, Kang C, Chia CSB, et al (2015) Targeting the central pocket in human transcription factor TEAD as a potential cancer therapeutic strategy. Structure 23, 2076-2086.

59. Gibault F, Coevoet M, Sturbaut M, Farce A, Renault N, Allemand F, Guichou J-F, Drucbert A-S, et al (2018) Toward the discovery of a novel class of YAP-TEAD interaction inhibitors by virtual screening approach targeting YAP-TEAD protein-protein interface. Cancers 10, ID 140.

60. Smith SA, Sessions RB, Shoemark DK, Williams C, Ebrahimighaei R, McNeill MC, Crump MP, McKay TR, et al (2019) Antiproliferative and antimigratory effects of a novel YAP-TEAD interaction inhibitor identified using in silico molecular docking. $J$ Med Chem 62, 1291-1305.

61. Noland CL, Gierke S, Schnier PD, Murray J, Sandoval WN, Sagolla M, Dey A, Hannoush RN, et al (2016) Palmitoylation of TEAD transcription factors is required for their stability and function in Hippo pathway signaling. Structure 24, 179-186.

62. Bum-Erdene K, Zhou D, Gonzalez-Gutierrez G, Ghozayel MK, Si Y, Xu D, Shannon HE, Bailey BJ, et al (2019) Small-molecule covalent modification of conserved cysteine leads to allosteric inhibition of the TEAD-Yap protein-protein interaction. Cell Chem Biol 26, 378-389.

63. Kurppa KJ, Liu Y, To C, Zhang T, Fan M, Vajdi A, Knelson EH, Xie Y, et al (2020) Treatment-induced tumor dormancy through YAP-mediated transcriptional reprogramming of the apoptotic pathway. Cancer Cell 37, 104-122.

64. Pobbati AV, Mejuch T, Chakraborty S, Karatas H, Bharath SR, Guéret SM, Goy P-A, Hahne G, et al (2019) Identification of quinolinols as activators of TEAD-dependent transcription. ACS Chem Biol 14, 2909-2921.

65. Holden JK, Crawford JJ, Noland CL, Schmidt S, Zbieg JR, Lacap JA, Zang R, Miller GM, et al (2020) Small molecule dysregulation of TEAD lipidation induces a dominant-negative inhibition of Hippo pathway signaling. Cell Rep 31, ID 107809. 